\title{
Opiniones de los profesionales de la comunicación sobre el tratamiento de la discapacidad en televisión
}

\section{Journalists' opinions about the treatment of disability on television}

\author{
Ma Eugenia González Cortés*, Inmaculada Montes Rodríguez**, Francisco Javier Paniagua Rojano*** \\ * University of Málaga, Spain \\ $* *$ Journalist \\ *** University of Málaga, Spain
}

Resumen

\begin{abstract}
La atención que prestan los medios de comunicación españoles a la audiencia con discapacidad continúa siendo limitada, en una sociedad donde el número de personas con discapacidad alcanza los 3,8 millones, lo que supone el $8,5 \%$ de la población. En este estudio se recogen las opiniones de siete profesionales de la comunicación que trabajan o han trabajado como directores, productores y/o presentadores de programas de televisión centrados en este público específico. A partir de entrevistas en profundidad, ofrecen una visión general del tratamiento mediático de la discapacidad, la sensibilización de las audiencias y el papel de los medios en relación a las minorías sociales. La muestra, a pesar de ser reducida, presenta un valor añadido: tres de las personas entrevistadas tienen una discapacidad, siendo sus opiniones especialmente relevantes por tratarse de la propia voz de un colectivo que es objeto de estudio. Se incluye, además, una radiografía de la programación televisiva española relacionada con la discapacidad. Los resultados obtenidos muestran la existencia de un mayor compromiso de los medios públicos, que apuestan por programar espacios que fomenten la normalización y la integración social de las personas con discapacidad, aunque se hace necesario una atención más continuada y menos episódica, y una mayor especialización periodística.
\end{abstract}

Palabras clave: discapacidad, televisión, medios de titularidad pública, minorías sociales, accesibilidad.

Abstract

\begin{abstract}
The attention paid by the Spanish mass media to audiences with disabilities remains limited, in a society where the number of people with disabilities reaches 3.8 million, representing $8.5 \%$ of the population. This study includes the opinions of seven journalists who work or have worked as directors, producers and/or anchormen of television programs focused on this specific audience. Analyzing their interviews, we provide a view of the media treatment of disabilities, the awareness of the audience and the role of the media related to social minorities. It also includes a portrayal of the Spanish television programming related to disability. The results show the existence of a greater compromise of the public media, which is committed to program spaces that encourage normalization and social integration of people with disabilities, even though it is necessary to have a more continuous and less episodic attention, and a greater journalistic specialization.
\end{abstract}

Keywords: disability, television, public mass media, social minorities, accessibility.

\section{Introducción: Minorías y medios de comunicación}

¿Qué se entiende por minorías sociales y por qué es necesario estudiar la atención que los medios de comunicación prestan a la discapacidad y a las personas con discapacidad como públicos y audiencias estables de sus productos?

Según recoge Begoña Pernas, citando a Louis Wirth, "minoría es cualquier grupo de personas que, a causa de sus características físicas o culturales, se encuentra sometido a una discriminación respecto de los demás miembros de la sociedad en la que vive, recibiendo de ésta un trato diferente e incluso injusto" (Wirth, 1945, 
en Pernas, 2010). Nos encontramos ante un concepto amplio ya que no define el tamaño de ese grupo ni ningún rasgo objetivo indiscutible del mismo. De esta forma, se podrían catalogar como minorías a aquellos colectivos que de alguna manera se ignoran o marginan por su orientación sexual o religiosa, su idioma, su etnia o su discapacidad física o psíquica, entre otros (Pernas, 2010). No existe una definición de minoría aceptada universalmente, sino que, como apunta Corona Ferreyra (2006), existen definiciones doctrinales, legales, interpretaciones judiciales o elementos objetivos y subjetivos que la integran. Sin embargo, no es éste el eje del trabajo, y sí lo es analizar la relación entre comunicación y minorías o, más concretamente, entre medios y discapacidad.

El trato de las minorías resulta importante por cuanto aparecen cuestiones relacionadas con la discriminación, los estereotipos y los prejuicios que dificultan la convivencia en una sociedad democrática. Es en este proceso donde los medios de comunicación juegan un papel central como creadores de imágenes e identidades en la opinión pública. Ya en 1922 Walter Lippmann en su obra Opinión pública trata de la formación de un modelo de opinión pública dependiendo de los medios de comunicación. Según Lippmann, los medios de información son una fuente primaria, aunque no única, de las imágenes y de las ficciones que tenemos en nuestras mentes y con las que se llega a formar opinión pública. Los medios en la transmisión de información tienden a reducir la realidad a estereotipos. El autor los especifica como "las imágenes que hay en la cabeza de estos seres humanos, las imágenes de ellos mismos, de los demás, de sus necesidades, intenciones y relaciones, son sus opiniones públicas. Las imágenes con arreglo a las que actúan grupos de personas, o individuos que actúan en nombre de grupos, son la Opinión Pública con mayúsculas" (Lippmann, 1965: 18). Al igual que él, Luhmann en un ensayo publicado en 1971 reveló aspectos desconocidos de la dinámica de la opinión pública, y ambos insistían en la relación entre la opinión pública y el periodismo. Convertidos en poderosas instituciones sociales y socializadoras, los medios crean y transmiten estos estereotipos. Así, la visión que se adquiere de cualquier tipo de minoría viene marcada por la influencia del discurso mediático. En los contenidos que emiten los medios, la escasa visibilidad y la infrarrepresentación de grupos minoritarios o en riesgo de exclusión social que han puesto de manifiesto numerosos estudios (Aguado \& Alcedo, 1991; Jackson, 1994; Sampedro, 2004; Díaz Aledo, 2007; Igartua et al., 2007; Fernández-Cid, 2010; Retis, 2010; Creighton, 2013) amenazan con obstruir uno de los ideales centrales de la sociedad democrática: la tolerancia de lo diferente en la convivencia de los distintos actores dentro del espacio público. Pobres, mujeres, minorías sexuales y políticas, personas con discapacidad, etcétera, continúan siendo estereotipados, criminalizados o excluidos del discurso masivo que privilegian los grandes medios de comunicación. Por estos motivos, se hace necesario analizar la presencia y la atención que merecen los públicos minoritarios en el entramado mediático español y, en este caso concreto, las personas que tienen una discapacidad, ya sea física, intelectual o mental.

\section{Estado de la cuestión}

Los últimos datos ofrecidos por el Instituto Nacional de Estadística (INE) sobre la población con algún tipo de discapacidad datan de $2008^{1}$, cuando la Encuesta de Discapacidad, Autonomía personal y situaciones de Dependencia (EDAD) señala que 3,85 millones de personas en España sufría entonces algún tipo de

\footnotetext{
${ }^{1}$ Hasta la fecha se trata de los más recientes, dado que no será hasta finales de 2017 cuando el INE publique los datos de una nueva encuesta.
} 
discapacidad o limitación, lo que representaba un $8 \%$ de la población. Conforman una cifra que ha de ser tenida en cuenta como consumidores de medios de comunicación. Veamos cuáles son los estudios que se han realizado sobre comunicación-discapacidad.

La representación mediática de la discapacidad ha sido y es objeto de preocupación en la investigación académica. Ya desde los años 80 , y especialmente en los 90 , se establece una clara relación entre la percepción social de la discapacidad y los medios de comunicación, otorgando a éstos un papel responsable (Del Río, 1986; Duncan, 1986). La mayoría de los estudios concluyen que los medios de comunicación, en general, no les prestan la atención informativa que merecen y que cuando se refieren a ellas el tratamiento no es el adecuado (Aguado \& Alcedo, 1991; Díaz Aledo, 2007; Solves, 2008). Esta preocupación pronto se verá reflejada en documentos y libros de estilo que promueven una normalización del lenguaje para referirse a la discapacidad, y que desaconsejan y denuncian conceptos peyorativos para adoptar otros que no discriminen a las personas en función de sus diferentes capacidades (CERMI, 2004). Ya a finales de los 80 Casado, Coleto, Martínez \& Sánchez publican Discapacidad y medios de información: Esquema para un libro de estilo (1989). El Real Patronato sobre Discapacidad edita su Guía de estilo de la discapacidad para profesionales de los medios de comunicación (Fernández Iglesias, 2006). Incluso organismos gubernamentales, como es el caso de la Junta de Andalucía, han publicado más recientemente textos similares como la Guía de buenas prácticas sobre personas con discapacidad para profesionales de la comunicación (Álvarez Pérez et. al., 2013).

Otra cuestión que ha despertado un creciente interés académico en el ámbito discapacidad-comunicación es la accesibilidad: el análisis del cumplimiento de las normativas por las que se regulan la incorporación de la lengua de signos, la audiodescripción o el subtitulado a los medios audiovisuales, y la accesibilidad web (Alba, Zubillaga del Río y Ruiz, 2003; Orero, 2005; Casado, 2007; Orero, Pereira \& Utray, 2007; Utray, 2009; Echegaray, Utray \& Delgado, 2010; Moreno Martínez et. al, 2011).

Algunos estudios se han centrado en aspectos específicos, como por ejemplo en el tratamiento de los deportistas con discapacidad a través del análisis de la cobertura mediática de las Paralimpiadas (Pappous et al., 2007, Pappous, Marcellini \& de Léséleuc, 2009, Rius \& Solves, 2012, Solves, 2012; Álvarez \& Mercado, 2015). Así como en el tratamiento mediático de la discapacidad a partir del análisis de los distintos sectores de la comunicación de masas, como la prensa, la televisión, la radio, la publicidad o el cine.

A pesar de todas estas referencias, escasean las investigaciones centradas en: a) las personas con discapacidad como públicos y audiencias estables de los medios de comunicación; b) la participación de personas con discapacidad en la producción de contenidos mediáticos y c) las opiniones, actitudes y expectativas de las mismas, como consumidores, sobre el tratamiento de la discapacidad en los medios (Pérez y Sepúlveda, 2009; Utray, Eyzaguirre y Ruiz, 2010; González Cortés, 2011; Arroyo, 2013). Este trabajo pretende continuar la investigación en este sentido, incorporando a las personas con discapacidad como públicos activos e incluso como productores de contenidos -especializados o no- en los medios de comunicación españoles. 


\section{Objetivos, hipótesis y metodología}

Este trabajo persigue dos objetivos principales: 1) Conocer la opinión de los profesionales de los medios sobre varias cuestiones del binomio discapacidad-comunicación y 2) Observar el tratamiento y la presencia de la discapacidad en la televisión pública española, mediante el análisis de los programas que, dirigidos al público en general, abordan esta temática o que están realizados por/para personas con discapacidad como públicos más específicos. Normalmente, estos espacios tratan de llegar a toda la audiencia, dado que la integración es cosa de dos.

Otros objetivos secundarios son:

- Estudiar si, en atención a la diversidad social, la televisión pública española cumple con la función de servicio a la ciudadanía que le es propia.

- Determinar cuál es la valoración e importancia que otorga a la discapacidad.

Las hipótesis que formulamos son:

H1: La implicación de los medios de comunicación de carácter público a la hora de abordar la discapacidad -bien sea mediante la emisión de programas realizados por/para personas con discapacidad, bien mediante la inclusión de esta temática en programas destinados a audiencias generalistas- es mayor que la de los medios privados.

H2: Los programas realizados para/por por personas con discapacidad o sobre esta temática tienen, no obstante, un papel relegado en las parrillas de programación, con una presencia escasa en las mismas y en huecos horarios residuales que no ocupan franjas destinadas a grandes segmentos de audiencia.

H3: Los escasos espacios televisivos que se emiten persiguen una normalización de la discapacidad, desde el conocimiento, y están alejados de una visión victimista o catastrófica y, por ende, sensacionalista.

\section{Metodología}

Hemos optado por dos herramientas metodológicas complementarias, que consisten en: 1) por un lado, observar las parrillas de programación para cuantificar los espacios relacionados, directa o indirectamente, con la discapacidad. 2) Por otro, realizar una entrevista en profundidad a profesionales de la comunicación que son expertos en la materia, por haber participado en calidad de directores, productores o presentadores de estos espacios. En total, siete entrevistas, que presentan un valor añadido: tres de ellas realizadas a personas con discapacidad, dos ciegas y una con síndrome de Down. Sus opiniones son especialmente relevantes por tratarse de la propia voz del colectivo que es objeto de estudio. 
Así, por un lado, se ha realizado una radiografía de las cadenas de televisión nacionales TVE1, La 2, Antena3, Telecinco, Cuatro y La Sexta observando los espacios o programas destinados a las personas con discapacidad que incluyen en sus parrillas. Adelantamos que en ninguna de las privadas se encontraron espacios de esta naturaleza.

Se contempla únicamente la televisión por ser el medio de mayor penetración en la población, con un 86,8\% de espectadores y un consumo de 222 minutos por persona al día (última oleada EGM, abril-marzo 2017). Respecto a la entrevista, se optó por un cuestionario abierto, donde el flujo conversacional derivó hacia conocimientos cognoscitivos de gran interés para este trabajo, así como hacia creencias, expectativas y deseos de los entrevistados que apuntaban a una televisión más inclusiva y de menor calado comercial. Como desventaja, hay que señalar que al tratarse de una técnica de investigación cualitativa los resultados no resultan extrapolables, tanto por la escasez de la muestra empleada como por la no representatividad de la misma.

A continuación, presentamos un listado de los/las profesionales entrevistados/as:

- Álvaro García Moro, director y productor de los programas Un mundo mejor y Piensa en positivo, emitidos en La 2, de TVE.

- Javier Calvo, director de la serie Capacitados, de La 2.

- Juan Antonio Sacaluga, director de Nosotros también, de La 2.

- Lola Hernández, directora del programa En lengua de signos, emitido en La 2.

- José Miguel Vila, periodista ciego. Fue director y presentador de Canal 11 (emisora de la ONCE (Organización Nacional de Ciegos Españoles) cuando era propietaria de Onda Cero.

- Nuria del Saz, que en 1998 se convirtió en la primera presentadora ciega de informativos de televisión, en Canal Sur, de RTVA, emisora también de titularidad pública.

- Pablo Pineda, primera persona en Europa con síndrome de Down en obtener un título universitario, presentador del programa de La 2 Piensa en positivo.

\section{Resultados}

Respondiendo a los dos objetivos principales de este trabajo, recogemos en primer lugar un compendio de las declaraciones extraídas de las entrevistas en profundidad, en total siete entrevistas, que ofrecen una visión general sobre el tratamiento mediático de la discapacidad; a continuación, trazamos un mapa de los programas que se emiten o se han emitido recientemente en TVE, la televisión pública española, acompañados de una breve descripción.

La opinión de los profesionales de la comunicación

La H1 planteaba una mayor implicación de los medios de comunicación de titularidad pública en la emisión de programas que promuevan un mejor conocimiento de la discapacidad. A raíz del análisis comparativo de 
la programación de las cadenas públicas y privadas (en estas últimas no se ha encontrado ningún espacio de estas características) y también según los expertos consultados, esta hipótesis se verifica. Así lo formula Javier Calvo:

TVE tiene una implicación casi como por obligación, se marca un porcentaje de horas y ya está. Debería existir una vocación y decir 'vamos a dedicarnos a programas de este ámbito', igual que le dedica sus espacios a la religión. Por lo que respecta a las privadas, olvidémonos, ningún interés en este tema, y ese es el problema.

Javier Calvo, director de Capacitados.

Efectivamente, la normativa de RTVE, la Radio Televisión Española, contempla a las audiencias con discapacidad. Así en su artículo quinto la Ley 4/1980, de 10 de enero, de Estatuto de la Radio y la Televisión recoge que la programación deberá "propiciar el acceso de todos a los distintos géneros de programación y a los eventos institucionales, sociales, culturales y deportivos, dirigiéndose a todos los segmentos de audiencia, edades y grupos sociales, incluidas las minorías con discapacidades". También el Manual de Estilo de $R T V E$, que reúne un conjunto de directrices para sus profesionales, incluye su apartado 5 sobre 'Cuestiones sensibles'. El título 5.13 'Discapacidad y enfermedad' recoge algunas recomendaciones léxicas y de tratamiento visual en la cobertura de noticias relacionadas con la discapacidad.

Sin embargo, los entrevistados consideran al mismo tiempo que esta implicación de los medios públicos no es suficiente. La atención a las personas con discapacidad, según manifiestan, viene marcada por la legislación (en España la ley ${ }^{2}$ obliga a las cadenas a emitir un determinado porcentaje de su programación subtitulada o en lengua de signos, para sordos, y audiodescrita, para ciegos), existiendo una falta de vocación verdadera:

En un país en el que pagamos todos esta televisión pública debería ser de obligado cumplimiento tener siempre en una determinada franja horaria un programa a favor de este colectivo, donde se vieran ellos de alguna manera más representados, donde se pudieran dar pautas o consejos. Intentan cumplir, dar esa imagen social, pero por mi experiencia no es así. Siguen basándose en los datos de audiencia (...). Si hubiera realmente una implicación social y humana en este aspecto, el tratamiento no sería el mismo (...) Un país no se puede jactar de ser moderno si esta situación no se tiene más que normalizada, y una forma de normalizarlo es estando en los medios de comunicación.

Álvaro García Moro, Un mundo mejory Piensa en positivo.

Dan pasos positivos en ese aspecto pero a veces porque queda bien, por vender una imagen. Es cierto que Canal Sur 2 ahora se dedica a emitir contenidos con un intérprete de signos, que se subtitula, etc. pero la accesibilidad no debería pensarse solamente para personas ciegas o sordas, sino también para el resto de la población: hay personas mayores que no ven o no escuchan bien, que tienen problemas de movilidad... Hay que crear, en definitiva,

\footnotetext{
${ }^{2}$ La Ley 7/2010, de 31 de Marzo, General de la Comunicación Audiovisual, en su artículo 8, disposición transitoria quinta, obligaba a los canales públicos a que ya en 2013 subtitulasen el $90 \%$ de los programas y contasen con 10 horas semanales de interpretación con lengua de signos y 10 horas audiodescritas.
} 
entornos más accesibles para una mayor calidad, pero debiera hacerse por vocación y no por obligación.

Nuria del Saz, presentadora de informativos.

En definitiva, los entrevistados recalcan que se han de evitar las iniciativas llevadas a cabo para "maquillar" la labor de los medios públicos y apostar en firme por programas que sigan una línea positiva, que muestren las capacidades de este colectivo, pensando no sólo en el mismo sino también en el resto de la sociedad. La H2 enunciaba que los programas realizados por/para personas con discapacidad o sobre esta temática tienen un papel relegado en las parrillas de programación, al ser escasos y al estar emitidos en malos horarios. Veamos algunas opiniones al respecto:

Habitualmente se ponen en unos horarios terribles, quizá falta algo más de empatía y ponerse en la piel de las personas con discapacidad. Pero hay que seguir luchando para poder acceder a esa información aunque sea a través de otros soportes como Internet, el cine, la publicidad... Programar no debería ser una cuestión de dinero, sino de pensar y diseñar los contenidos y programarlos para que sean más accesibles tanto para personas discapacitadas como sin discapacidad.

Nuria del Saz.

Me encantaría que se pudiera apostar por este tipo de formatos a otras horas y se le diera más repercusión, pero hay muchas teorías para argumentar lo contrario. La audiencia dice que con este tipo de programas acaba siempre llorando, algo con lo que personalmente no estoy de acuerdo porque en nuestro caso se resaltaban los aspectos positivos, huyendo de tocar la fibra. Defendíamos tener una ventana donde mostrábamos una realidad contada como tiene que ser para que la gente sacara sus propias conclusiones.

Álvaro García Moro.

Pienso que se minusvalora al telespectador. Creemos que sólo puede ver realities o que intelectualmente no le puede interesar ciertas cosas y se les da otras. Así nadie se atreve a probar, a poner un determinado programa de este ámbito en prime time en ninguna cadena, o si no es ahí después del prime time. Simplemente por la curiosidad y si el producto es bueno, el reducto de audiencia que quede va a ver el programa (...) Es una cuestión de programadores y del concepto que se tiene del público, de entender que sólamente quieren un tipo de programa y de no asumir ningún riesgo.

Javier Calvo.

Una visión distinta sobre este aspecto comparten José Miguel Vila y Juan Antonio Sacaluga, quienes restan importancia al horario de emisión o cuestionan la conveniencia de colocarlos en franja de máxima audiencia:

La cuestión es que los valores que rigen actualmente en la sociedad no ayudan mucho a que se visualice la discapacidad. Pero de todas maneras, quizá tampoco tengan que tener esos 
programas más visión, la discapacidad no es problema ni es un asunto esencial en la sociedad actual, no es lo que la gente busca. No se trata de ocupar el prime time sino de tener presencia y que la gente sepa dónde acudir cuando tiene algún problema.

José Miguel Vila.

No son programas mayoritarios y hasta cierto punto comprendo que no tengan mucha visión por ese hecho. No es tanto ese el problema. Para mí, la reivindicación más importante es que en las redacciones, sobre todo en las secciones de Sociedad, haya profesionales que por lo menos tengan una cierta formación [en discapacidad].

Juan Antonio Sacaluga.

Al margen de las opiniones recogidas, observamos que muchos de los programas han tenido, por el contrario, una situación privilegiada en las parrillas. Sólo dos de ellos están actualmente en antena: Con mis ojos, que se emite los domingos a las 21.00 horas, y En lengua de signos, los sábados a las 11.00. Generalmente se han programado durante los fines de semana, en las franjas de mañana (entre las 09.30 y las 12.30 ) o de tarde (entre las 19.00 y las 21.00 ).

Pablo Pineda, primera persona en Europa con síndrome de Down en obtener un título universitario y presentador del programa de La 2 Piensa en positivo, apunta a que la plena normalización de la discapacidad va más allá de la producción de espacios específicos dedicados a este colectivo. Es necesaria la inclusión de personas con discapacidad en todo tipo de espacios, su presencia habitual y no excepcional en los medios, como integrantes de la sociedad:

Creo que debiera ser más bien lo contrario: programas normales, de debate, en los que opinamos y decimos lo que pensamos. No existen programas así. Muchas veces se hacen programas especiales a medida para determinado tipo de discapacidad, en mi caso sobre síndrome de Down; sin embargo, puedo decirte que me da rabia cuando veo que no hay una persona con síndrome de Down en un programa de debate como tertuliana. Creo que eso sería un grandísimo paso: vernos como una persona que tiene ideología, opiniones, criterio...

Pablo Pineda, presentador de Piensa en positivo.

La H3 planteaba que los escasos espacios televisivos que se emiten persiguen una normalización de la discapacidad desde el conocimiento, y están alejados de una visión victimista o catastrófica y, por ende, sensacionalista. En efecto, todos los entrevistados coinciden en que estos programas pretender normalizar, desde la concepción de que tener una discapacidad no se traduce en ser incapaz ni improductivo. Es el caso de la serie Capacitados, que, como indica su director, Javier Calvo, nació para mostrar las capacidades de esta minoría: "Lo que nos hace capaces o 'discapaces' es el entorno, no nosotros", explicaba. Con este mismo objetivo planteó Juan Antonio Sacaluga el programa Nosotros también:

Lo que quería demostrar con esto es que las personas con discapacidad, con los apoyos necesarios y precisos, podían hacer muchas más cosas de las que la sociedad les permitía hacer; por ejemplo, un programa de televisión. Esas personas iban a mostrar en pantalla sus 
limitaciones, como tenemos todos, pero también se iba a poder ver cómo con los apoyos adecuados podían proyectar su propia imagen, hablar de sus aspiraciones o problemas directamente y sin mediadores. Además, cumplía con los que son los principios generales de la programación de TVE, de participación ciudadana, respeto, apoyo y promoción de los derechos de las minorías.

Juan Antonio Sacaluga.

Coinciden en que el objetivo es fomentar la integración y que en ningún caso se pretende tocar los resortes emocionales de la audiencia o tender al sensacionalismo. De esta forma hablaron sobre el comienzo de sus programas y su finalidad:

Tuvo varias finalidades y creo que se han cubierto todas: una era dejar una memoria escrita de que alguna vez existió un canal, que era Canal 11, que hacía radio para personas con discapacidad visual y, por otro lado, que se conociera que ser ciego no significa tener limitaciones. Si uno tiene voluntad, fuerza y capacidad, puede llegar a ser lo que se proponga. En las entrevistas que realizábamos hay 50 ejemplos de personas ciegas que han hecho muchas cosas probablemente insospechadas para la gente: hay navegantes que han dado la vuelta al mundo, pianistas, empresarios, políticos, comerciales, abogados, periodistas, economistas, diplomáticos, sacerdotes, actores... Prácticamente cualquier actividad de la sociedad puede ser desempeñada por una persona ciega o con otro tipo de discapacidad y con la misma calidad que cualquier otra persona.

José Miguel Vila sobre Canal 11.

En nuestro caso nunca hemos tratado de que el espectador sienta pena sino todo lo contrario. Tratamos de darle cierta normalidad y que la gente vea que las personas sordas son personas como cualquier otra. Todos somos diferentes.

Lola Hernández, directora de En lengua de signos.

El trato de espectáculo quizá se da más en las cadenas privadas pero nosotros huíamos de esos sentimientos primarios y lo tratábamos desde la igualdad y en positivo.

Javier Calvo.

Destaca el hecho de que, en ocasiones, una motivación personal, un contacto directo con la discapacidad, se convierte en el germen de futuras emisiones en antena:

Fue una idea personal, ya que tengo una hija con autismo. Según lo que veía por mi doble condición de padre y periodista, entendí que había una clara disfunción entre la percepción pública de la discapacidad y el tratamiento que los medios hacían de ella. Generalmente, la sociedad percibe las discapacidades de las personas, pero no sus capacidades.

Juan Antonio Sacaluga sobre Nosotros también. 
De forma paulatina, ha avanzado el conocimiento de la discapacidad, mejorándose las cotas de visibilidad, normalización y sensibilización social. Sin embargo, algunos entrevistados sostienen que, a pesar de las buenas intenciones, cuando se aborda la discapacidad en las noticias nos topamos con falta de contextualización, con ciertas dosis de sensacionalismo y con un lenguaje negativo, afectado o reduccionista, que resalta su condición y no sus valores. Las principales quejas hablan de un tratamiento mediático sesgado, estereotipado, institucionalizado, marginal, descontextualizado, tendente a la espectacularización, simplificado, superficial, no participativo y, en general, erróneo.

Sin duda, la evolución experimentada en el lenguaje ha servido para provocar un avance en la concepción de la discapacidad; difícilmente se escuchan términos tan peyorativos como "subnormal" o "retrasado", y por supuesto nunca en los medios de comunicación. Otros, como "minusválido", continúan extendidos a pesar de su inadecuación:

Es curioso lo de la terminología porque, además, la organización que surgió en los años 60 para defender los derechos de las personas con discapacidad intelectual se llamaba, y se llama, Federación Española de Asociaciones Pro Subnormales. Son todos términos peyorativos, que respondían a una visión social de la discapacidad bastante negativa. Eso ha cambiado pero queda aún mucho por hacer.

Juan Antonio Sacaluga.

Se han publicado documentos que recogen recomendaciones de carácter léxico y de tratamiento lingüístico y gráfico de la discapacidad como, por ejemplo, la Guía de buenas prácticas sobre personas con discapacidad para profesionales de la comunicación (2013), o el manual de estilo Periodismo social. El compromiso de la información, que aborda este tema, entre otros; se han celebrado encuentros, congresos y simposios, como el I Encuentro sobre Periodismo y Discapacidad, en 2004, del que surgió la Declaración de Salamanca en la que los profesionales de la comunicación se comprometieron a tratar en sus respectivos medios el tema de la discapacidad siguiendo unas pautas de estilo y contenido que ayudaran a olvidar viejos prejuicios y un vocabulario inadecuado. O la más reciente jornada celebrada por la Federación de Asociaciones de Periodistas de España (FAPE) y la Fundación Carmen Pardo-Valcarce (FCPV) en octubre de 2016, donde se presentó el informe Tratamiento informativo de personas con discapacidad, elaborado por la Comisión de Arbitraje, Quejas y Deontología del Periodismo de la FAPE.

No obstante, de nuevo y a pesar de que los medios de comunicación son cada vez más sensibles con este colectivo, las rutinas profesionales, la celeridad y la falta de especialización y conocimiento frenan el desarrollo en el tratamiento de la discapacidad.

Continuamente se publican guías para periodistas sobre el lenguaje y la discapacidad, pero sigues escuchando en los medios expresiones bastante desafortunadas. Creo que los profesionales siguen un poco perdidos al respecto, porque de una forma experiencial la discapacidad es algo que les toca de lejos, no conocen su realidad y se siguen cometiendo errores (...) Los medios contribuimos a dar a la ciudadanía una imagen de la discapacidad lo más real posible, pero depende del periodista y del programa: unos son más sensibles y procuran tratar e informar sobre la discapacidad con rigor y respeto; y otros lo hacen a su 
manera. Por eso hay que escuchar más a los colectivos de discapacitados porque al fin y al cabo ellos son quienes verdaderamente conocen su realidad.

Nuria del Saz.

Hay un gran desconocimiento. Seguramente un reportero que no conoce y que no se ha metido de verdad en ese universo lo ve todo con más condescendencia.

Javier Calvo.

Generalmente en los medios hay buena voluntad, pero un desconocimiento bastante profundo de muchas de las discapacidades, sobre todo de las intelectuales. Se utiliza un lenguaje de oídas, de lo que se habla en la calle y a veces es inapropiado, sobre todo en temas que son muy sensibles (...). No vale con tener buena actitud o querer ser solidario, sino que hay que saber de qué se está hablando.

Juan Antonio Sacaluga.

Para trabajar con nosotros, desde mi punto de vista, sería imperdonable en un periodista no conocer o no saber hablar sobre ciertos temas relacionados con la sordera y no estar especializado en ese tema.

Lola Hernández.

Respecto a la percepción social y el grado de normalización y de conocimiento de la discapacidad, las opiniones de Nuria del Saz y Pablo Pineda son especialmente significativas para medir el camino que aún queda por recorrer:

A muchas personas con discapacidad se nos sigue viendo como algo especial, algo raro, como héroes de la vida o como dignos de lástima, aunque abiertamente no se diga y se tire de muletillas políticamente correctas. No se sabe actuar con naturalidad ante una persona con discapacidad, pero confío en que la integración en las escuelas favorezca una visión normalizada.

Nuria del Saz.

Poco a poco la sociedad va avanzando y los medios también. Se han involucrado en el tema pero aún falta. Tienen que ir abandonando esa idea e imagen negativas, y vernos como personas que disfrutamos de la vida. Dejar de lado el "sufre" o "padece", hablar de "personas" y no de "discapacitados", hablar de que "disfrutamos" y no de que "sufrimos", no hablar tanto de los grados porque no es verdad que haya grados... en fin, erradicar esa serie de términos negativos. Hace falta una renovación en cuanto a contenidos y en cuanto a palabras.

Pablo Pineda. 


\section{Espacios inclusivos en las parrillas de programación}

A continuación, recogemos los programas que se emiten o se han emitido recientemente en TVE, la televisión pública española, acompañados de una breve descripción:

- Capacitados. Con este título, TVE lanzó una serie de 13 episodios emitidos en La 2 en la que personajes famosos se prestaron a ponerse durante una jornada en la piel de una persona con discapacidad. Pasaron por este programa deportistas, como el ciclista Alberto Contador, el futbolista de la Selección Nacional Roberto Soldado o el jugador de baloncesto Rudy Fernández, los integrantes de la compañía de teatro Tricicle, políticos, , actrices, cantantes, etcétera. Dirigida por Javier Calvo y producida por Ovideo en colaboración con la ONCE, nació a raíz de una experiencia similar con empresarios. Capacitados tenía una duración aproximada de 30 minutos y se emitió por última vez el 6 de enero de 2013. Entre mayo y agosto de 2015 se emitió su segunda temporada, de 12 episodios. Cómo cantar cuando tienes problema de audición, disputar un partido de baloncesto desde una silla de ruedas o salir al campo de fútbol con un antifaz que te impide ver... El programa fue galardonado con el Premio Valores, según el jurado "por su valiente apuesta por promover una visión más empática, positiva y sobrecogedora de las barreras físicas que nos pueden separar". Su audiencia osciló entre el 0,6 y el 2,2 por ciento.

- Con mis ojos. Es un programa de viajes en La 2 de TVE en el que la protagonista Pilar, una persona ciega, recorre la geografía española con su perra guía, Kenzie, para acercar al espectador lugares, personajes y experiencias a través del tacto, el olfato, el oído y el gusto. El espacio cuenta con subtitulado para sordos y audiodescripción para personas ciegas. Dirigida por Gilbert Arroyo, se trata de una adaptación para España de Dans tes yeux, del canal público franco-alemán ARTE, cuya protagonista es también en este caso una mujer, Sophie. En España la serie se compuso de 11 programas de 30 minutos de duración, en los que pudimos ver a su protagonista disfrutando de las experiencias que cada rincón de España ofrece a los visitantes, como esquiar en la sierra, ordeñar una cabra, hacer escalada o, por qué no, surfing. La versión española se emitió por última vez el 27 de julio de 2014, y se sustituyó entonces por la francesa, aún en antena cada domingo, donde el recorrido que hace su protagonista, Sophie, es internacional. De nuevo, un ejemplo de potenciación de las capacidades de las personas con discapacidad, porque ver no es la única forma de conocer el mundo. Sintiendo, tocando, escuchando y oliendo también se puede.

- Con una sonrisa: Docurreality actualmente fuera de emisión que contó con 13 episodios, de media hora de duración, emitidos en La 2 de TVE. En él vemos cómo se hace realidad el mayor sueño de seis personas con discapacidad intelectual: tener un trabajo real y sentirse respetado y necesitado en el ámbito laboral. $\mathrm{A}$ lo largo de la serie los espectadores pudieron conocer a Gloria, Hugo, Irene, Javi, Laura y Luis, seis personajes que desempeñaron diferentes tareas como trabajadores de un hotel. Limpiar las habitaciones, registrar a los nuevos huéspedes, entregar los pedidos del servicio de habitaciones o preparar un menú de autor son algunos ejemplos. Estuvo patrocinado por Iberdrola y contó con la colaboración de la Fundación Síndrome de Down de Madrid. El último episodio se emitió el 11 de julio de 2013.

- El mundo se mueve contigo: Estuvo en antena desde marzo de 2010 hasta diciembre de 2012, conducido por la medallista olímpica de esgrima en las Paralimpiadas de Barcelona 92 y Atlanta 96 Gema Hassen-Bey. Emitido en La 2 de TVE, durante sus 30 minutos de duración, su presentadora -que además de ser deportista de élite es licenciada en Ciencias de la Información, actriz y compositora- realizaba entrevistas a expertos, 
recorría espacios públicos mostrando su accesibilidad y visitaba a personas con distintas discapacidades y, sobre todo, con capacidades diferentes (ya que desarrollaban disciplinas artísticas y/o deportivas).

- En lengua de signos. Informativo para personas sordas y oyentes actualmente en emisión. Se trata de un espacio que resume la actualidad del mundo para las personas sordas en su lengua (la lengua de signos) y con subtítulos, para sordos no signantes. Los contenidos de este informativo se traducen simultáneamente por una voz en off. Su objetivo, como reza en su web, es "alcanzar a todos sin exclusiones, rompiendo el silencio informativo que existe entre la televisión y las personas con discapacidad auditiva". Desde febrero de 2008, dirigido por Lola Hernández (experta entrevistada), se emite cada sábado a las 11.00 horas en La 2 de TVE. Con este programa se evidencia el compromiso de Televisión Española con el colectivo de personas con discapacidad auditiva, que en España son casi un millón, y que han contado desde 1997 -cuando comenzó a emitirse En otras palabras- con un informativo de estas características. Se trata del primer espacio en TVE presentado por una persona sorda, Paloma Soroa.

- Esto está muy bien: Mediante los testimonios de personajes conocidos, de encuestas en la calle, de opiniones de personas con discapacidad que se han incorporado a la vida laboral o, incluso, con cámaras ocultas, se mostraban las dificultades pero también las ventajas de la inclusión social de esta minoría. En total, una serie de cinco capítulos emitidos en diciembre de 2011.

- Nosotros también: Bajo la dirección de Juan Antonio Sacaluga (uno de los expertos entrevistados) este espacio abordaba los aspectos más sensibles del colectivo de personas con discapacidad intelectual en tres ámbitos principales: el empleo, el ocio y la vida privada. Fue un programa pionero no sólo en España, sino también en Europa, al estar realizado completamente por personas con discapacidad intelectual, quienes con los apoyos necesarios se encargaban de presentar, participar en los debates, hacer los decorados, elegir los contenidos y elaborar los reportajes y las noticias que incluía. No era un programa sobre la problemática de las personas con discapacidad, sino que mostraba las aportaciones de este colectivo a la sociedad. Se emitió un domingo al mes, a las 12.30 horas en La 2 de TVE, entre abril de 2007 y julio de 2011.

- Piensa en positivo: El formato, pensado para potenciar la integración en el mercado laboral, se estrenaba el 21 de septiembre de 2013 y estuvo en antena hasta el 7 de diciembre del mismo año; en total doce capítulos que se fueron emitiendo semanalmente, presentados por Pablo Pineda. Pineda es una cara famosa en España, no sólo por ser la primera persona con síndrome de Down que obtiene un título universitario en Europa, sino por su papel protagonista en la película Yo También, que narra la historia de un trabajador social Down que se enamora de su compañera de trabajo. Esta interpretación le valió la Concha de Plata en San Sebastián. Dos son los ejes de Piensa en positivo: discapacidad y trabajo. Cada programa se centraba así en una temática concreta: formación, reclutamiento, sensibilización, adaptación, acompañamiento, etcétera, y contaba con la participación de empresas que han incorporado la discapacidad dentro su cadena de valor y que han sido reconocidas por ello.

- Sin Barreras. Actualmente fuera de emisión. En este docurreality de La 2 de TVE, el músico ciego Serafín Zubiri mostraba su faceta menos conocida en tres entregas de una hora de duración que promovían el espíritu de superación de las personas con discapacidad a través del deporte. Se estrenó en noviembre de 2012 y se emitía los domingos por la tarde en La 2, con el patrocinio de la Fundación ONCE. En los diferentes capítulos vimos al artista enfrentarse a diferentes retos: desde hacer submarinismo, rafting, escalada o saltar en parapente hasta correr la media maratón de Roncesvalles (Navarra) tratando así de derribar algunos prejuicios sobre las personas ciegas. 
- Tengo once años. Espacio que fue emitido los domingos por la tarde en La 2 y producido por enminúscula (Grupo Secuoya) para TVE con la colaboración de la Fundación ONCE. Constó de seis entregas semanales, entre enero y febrero de 2014, en las que se trató de dar la visión -en primera persona- de la discapacidad desde la mirada natural y desprovista de prejuicios de seis niños de once años. El programa, de 30 minutos de duración, incidía de forma especial en el día a día del niño, bien porque tenía una discapacidad bien porque la tenía alguien de su entorno más cercano (desde sus propios padres hasta hermanos o tíos).

- Todos somos raros, todos somos únicos. Programa de carácter divulgativo que forma parte del movimiento con el mismo título (www.todossomosraros.es), promovido junto a la Fundación Isabel Gemio, la Federación Española de Enfermedades Raras y la Federación Española de Enfermedades Neuromusculares. Actualmente fuera de emisión, trataba de sensibilizar a los espectadores sobre las más de 8.000 enfermedades infrecuentes que afectan a más de tres millones de personas en España. Entre enero y marzo de 2014 se emitieron nueve programas, siete de ellos de 30 minutos de duración. Los dos últimos fueron especiales, y recogieron un telemaratón solidario al que asistieron muchos personajes famosos, que subastaron objetos personales e hicieron actuaciones, con el fin de recaudar fondos para la investigación científica. El primer telemaratón a nivel nacional por las enfermedades raras consiguió recaudar un total de 1.185 .000 euros. Porque todos somos diferentes y todos somos iguales.

- Un mundo mejor. Programa semanal emitido los domingos por la tarde en La 2 de TVE, presentado por Bertín Osborne y dirigido por Álvaro García Moro (uno de los expertos entrevistados). Constó de ocho entregas, emitidas entre septiembre y diciembre de 2012 , centradas en historias personales, de nuevo para normalizar la discapacidad desde el conocimiento, así como para fomentar el empleo entre las personas con discapacidad, mediante ejemplos de empresas y organizaciones que apuestan por la integración.

\section{Conclusiones}

Tras las entrevistas mantenidas y el análisis de las parrillas de televisión, podemos concluir que en efecto la televisión pública española considera a los públicos minoritarios en su programación, incluidas las minorías con discapacidad. Las televisiones privadas, bajo la tiranía de las cifras de audiencia, no programan ningún espacio de estas características. Esta implicación de TVE, que se refleja en ejemplos concretos de espacios hechos por/para personas con discapacidad de todo tipo, es calificada no obstante por nuestros entrevistados de insuficiente, no guiada por una vocación verdadera sino por el cumplimiento de los principios normativos incluidos tanto en el Estatuto de la Radio y la Televisión como en el Manual de Estilo de RTVE, donde se recoge que la programación deberá "propiciar el acceso de todos a los distintos géneros de programación y a los eventos institucionales, sociales, culturales y deportivos, dirigiéndose a todos los segmentos de audiencia, edades y grupos sociales, incluidas las minorías con discapacidades".

La mayoría de los programas relacionados con la discapacidad que se emiten o se han emitido en TVE suelen tener un número de entregas determinado, siendo menos habituales aquellos con una permanencia duradera en antena. No podemos concluir que sus horarios de emisión sean residuales y, como otro de sus aspectos positivos, es destacable el consenso de todos los entrevistados sobre el tratamiento de la discapacidad que hacen, alejado por lo general del sensacionalismo, de las actitudes paternalistas o caritativas, y orientados hacia la normalización. Esta normalización se consigue en la mayoría de los 
programas mostrando las capacidades de todo tipo (artísticas, deportivas, intelectuales, etcétera) de las personas con discapacidad. Sin embargo, y a pesar de todas estas características loables de la programación inclusiva, queremos terminar con una propuesta de actuación distinta, que apuntaba ya uno de los entrevistados, Pablo Pineda. Consideramos que la verdadera normalización no pasa por la existencia de unos espacios especializados, sino por la inclusión de la discapacidad y de las personas con discapacidad en la programación televisiva española, en todo tipo de programas, porque todas las personas somos diversas $y$ todas formamos $y$ hemos de formar parte real de la sociedad. Por ello, $y$ a pesar del avance observado en el tratamiento mediático de la discapacidad, este cambio de enfoque se hace necesario si queremos conseguir una transformación profunda en la percepción social.

\section{Bibliografía}

Aguado, A. L. \& Alcedo, M.A. (1991). Tratamiento de la discapacidad en la prensa asturiana. Psicothema, 3 (1), 175-198.

AIMC (2017). Estudio General de Medios, de abril a marzo de 2017. Madrid: Asociación para la Investigación de Medios de Comunicación.

Alba, C., Zubillaga del Río, A. \& Ruiz, N. (2003). Educación Superior y discapacidad: Accesibilidad de las páginas web de las universidades estatales. Comunicación y Pedagogía, 188, 25-30. Recuperado de:

http://www2.congreso.gob.pe/sicr/cendocbib/con4 uibd.nsf/AE5376AE97E835D905257C68005CF F84/\$FILE/Educacion Superior y discapacidad Accesibilidad.pdf

Álvarez Pérez, R. et al. (2013). Guía de buenas prácticas sobre personas con discapacidad para profesionales de la comunicación. Sevilla: Consejería de Salud y Bienestar Social. Recuperado de http://www.canalsur.es/resources/archivos/2014/9/18/1411033496031guia buenas practicas dis capacidad.pdf

Álvarez, M.A. y Mercado, M.T. (2015). La representación mediática del deportista con discapacidad en el reportaje televisivo. Informe Semanal, un estudio de caso. Revista Mediterránea de Comunicación, 6 (1), 27-43. doi:10.14198/MEDCOM2015.6.1.03

Arroyo, M.C. (2013). Terapia ocupacional en televisión: Escúchame. Revista TOG, 10 (8), 24-27. Recuperado de: http://www.revistatog.com/suple/num8/television.pdf

Casado, D., Coleto, F., Martínez, F. y Sánchez, M. (1989). Discapacidad y medios de información.: Esquema para un libro de estilo. Madrid: Real Patronato de Prevención y de Atención a Personas con Minusvalía.

Cermi (2004). Discapacidad. Nuevas realidades, nuevos términos. Madrid: CERMI.

Corona Ferreyra, R.R. (2006). Minorías y grupos diferenciados: claves para una aproximación conceptual desde la perspectiva internacional. IUS Revista Jurídica, 22. Recuperado de: http://www.unla.mx/iusunla22/reflexion/minorias\%20y\%20grupos\%20difernciados.htm

Creighton, H. (2013). (De) construir la otredad: las mujeres inmigrantes en la prensa escrita española. Revista de Paz y Conflictos, 6, 78-106. Recuperado de http://www.redalyc.org:9081/articulo.oa?id=205027536004 
Del Río Pereda, P. (1986). La imagen de las personas con deficiencia y el papel de los medios de comunicación. Madrid: Real Patronato de Prevención y de Atención a Personas con Minusvalía.

Díaz Aledo, L. (2007). La representación de la discapacidad en los medios de comunicación. Comunicación e cidadanía, 1, 289-306.

Duncan, B. (1986). Los medios de comunicación como motor de cambio de la percepción de la discapacidad por parte del público. Madrid: Fundesco.

Echegaray, L., Utray, F. \& Delgado, F.U. (2010, febrero). Servicios de accesibilidad universal a la televisión digital. Análisis de recepción con el colectivo de personas con discapacidad y mayores. En II Congreso Internacional de la Asociación Española de Investigadores de la Comunicación (AE-IC), Málaga, España.

EGM (2014). Estudio General de Medios. Asociación para la Investigación de Medios de Comunicación (AIMC).

Fernández-Cid, M. (2010). Medios de comunicación, conformación de imagen y construcción de sentido en relación a la discapacidad. Política y Sociedad, vol. 47 (1), 105-113. Recuperado de: http://revistas.ucm.es/index.php/POSO/article/view/POSO1010130105A/21696

Fernández Iglesias, J.L. (2006). Guía de estilo sobre discapacidad para profesionales de los medios de comunicación. Madrid: Real Patronato sobre Discapacidad.

González Cortés, M.E. (2011, diciembre). Algunos públicos minoritarios y olvidados: la atención mediática a las personas con discapacidad en la radio y televisión españolas. En III Congreso Internacional Latina de Comunicación Social, Universidad de La Laguna, España. Recuperado de: http://www.revistalatinacs.org/11SLCS/actas 2011 IIICILCS/173 Gonzalez.pdf

Igartua, J.J. et al. (2007). Efectos cognitivos y afectivos de los encuadres noticiosos de la inmigración. En Igartua, J.J. \& Muñiz, C. (Eds.), Medios de comunicación, Inmigración y Sociedad (197-232). Salamanca: Ediciones Universidad de Salamanca.

INE (2008). Encuesta de Discapacidad, Autonomía personal y situaciones de Dependencia. Instituto Nacional de Estadística.

Jackson, H.R. (1994). Minorías y mass media: de los 70 a los 90. En Bryant, J. \& Zillmann, D. (Comp.). Los efectos de los medios de comunicación: investigaciones y teorías (365-422). Barcelona: Paidós.

Lippmann, W. (1965). Public opinion. New York: Free Press.

RTVE (2010). Manual de estilo de la Corporación RTVE.

Moreno Martínez et. Al. (2011, junio). Sistema abierto de Televisión Digital Terrestre (TDT) accesible para personas con deficiencia visual. En V Congreso Internacional de Diseño, Redes de Investigación y Tecnología para todos, Madrid, España. Recuperado de: http://oa.upm.es/12438/1/INVE_MEM_2011_104823.pdf

Orero (2005). La inclusión de la accesibilidad en comunicación audiovisual dentro de los estudios de traducción audiovisual. Quaderns. Revista de Traducciò, 12, 173-185. Recuperado de: http://ddd.uab.cat/pub/quaderns/11385790n12/11385790n12p173.pdf

Orero, P. Pereira, A. \& Utray, F. (2007). Visión histórica de la accesibilidad en los medios en España. Trans. Revista de Traductología, 11, 31-44. Málaga: Universidad de Málaga. Recuperado de: http://www.trans.uma.es/pdf/Trans 11/T.31-430reroPereiraUtray.pdf

Pappous, A. et al. (2007). La visibilidad de la deportista paralímpica en la prensa escrita española. Revista 
de Ciencias del Ejercicio, 3 (2), 12-32.

Pappous, A., Marcellini, A. \& De Léséleuc, E. (2009). La representación mediática del deporte adaptado a la discapacidad en los medios de comunicación. Agora para la educación física y el deporte, 9, 31-42.

Pérez, Y. \& Sepúlveda, A. (2009). Dar Oídos. Una propuesta de televisión participativa para las personas en situación de deficiencia auditiva. Bogotá: Corporación Universitaria Minuto de Dios. Recuperado de: http://repository.uniminuto.edu:8080/jspui/bitstream/10656/467/3/TC PerezBarreraYoana 2009. pdf

Pernas, B. (2010). La discriminación de las minorías: Una introducción sociológica. Ponencia presentada en el curso sobre la discriminación de las minorías, organizado por el Instituto de Cultura Gitana y el Ministerio de Igualdad. Recuperado de: http://www.gea21.com/ media/equipo/bp/la discriminacion de las minorias.pdf

Retis, J. (2010). ¿Cómo reflejan los medios de comunicación a las mujeres inmigrantes latinoamericanas? Análisis de la prensa española y estadounidense. En Martínez Lirola, M. (Ed.), Migraciones, discursos e ideologías en una sociedad globalizada (57-78). Alicante: Instituto Alicantino de Cultura Juan Gil-Albert.

Rius \& Solves (2012). Periodismo social y discapacidad. El deporte adaptado en el discurso periodístico. En Fernández, J.J. \& Rubio, A.L. (Coord.), Prensa y periodismo especializado V(45-57). Guadalajara: Asociación de la Prensa de Guadalajara.

Sampedro, V. (2004). Identidades mediáticas. La lógica del régimen de visibilidad contemporánea. Sphera Pública (4). Recuperado de: http://www.redalyc.org/html/297/29700402/

Solves, J. (2008). Tratamiento de la discapacidad en los medios valencianos. En I+C Investigar la comunicación. Actas del I Congreso Internacional de la AE-IC, celebrado en Santiago de Compostela. Recuperado de http://www.aeic.org/tarragona2012/contents/comunicacions cd/ok/23.pdf

(2012). (Coord.). Tratamiento de los Juegos Paralímpicos de 2008 en los medios españoles. Madrid: Editorial Cinca. Recuperado de http://www.cermi.es/esES/Biblioteca/Lists/Publicaciones/Attachments/290/Colecci\%C3\%B3n\%20Cermi\%20esTratamiento\%20de\%20los\%20juegos\%20paralimpicos-N\%C2\%BA\%2056\%20\%282\%29.pdf

Utray, F. (2009). Accesibilidad a la TDT en España para personas con discapacidad sensorial (2005-2007). Madrid: Real Patronato sobre Discapacidad. Recuperado de: http://www.cesya.es/files/documentos/libroTDT baja.pdf

Utray, F., Echegaray, L. \& Ruiz, B. (2010). Actitudes y expectativas del colectivo de personas con discapacidad hacia la televisión. Pangea: Revista de la Red Académica Iberoamericana de Comunicación, 1 (3), 54-73.

Wirth, L. (1945). The problem of minority groups. En Ralph Linton (Ed.), The science of man in the world crisis (347-372). Nueva York: Columbia University Press. 